\title{
La infección como origen y desencadenante de enfermedades autoinmunes
}

\author{
F. BLASCO PATIÑO \\ Servicio de Medicina Interna II. Clínica Puerta de Hierro. Madrid
}

INFECTION LIKE ORIGIN OF ANTOIMMUNE DISEASES

Blasco Patiño F. La infección como origen y desencadenante de enfermedades autoinmunes. An Med Interna (Madrid) 2002; 19: 44-48.

\section{INTRODUCCIÓN}

"Te explicaré ahora cuál es la causa de las enfermedades... es innegable que circulan por el aire muchos gérmenes de enfermedad y muerte...". Con estas palabras recogidas en el libro VI De rerum natura (de la Naturaleza), Lucrecio señala la existencia de un agente común causante de las enfermedades, los gérmenes. Si bien el concepto de germen en el siglo II no era exactamente el que con la moderna microbiología se ha establecido, puede ser aproximado conceptualmente, en el sentido genérico de entes que están en el ambiente y que al entrar en el cuerpo origina la enfermedad.

No pretendo adoptar este concepto como un hecho absoluto, aunque lo cierto es que cada vez son más las entidades clínicas en las que comienza a describirse el papel de diversos microorganismos en su génesis. Sirvan de ejemplo el cada vez menos discutido papel del $H$. pylori en la ulcera gastroduodenal, o la asociación de numerosos virus con diversas neoplasias, como es el caso del virus de Epstein Barr y el linfoma de Burkitt, e incluso la actuación de la Clamydia trachomatis en la formación de la placa de ateroma y su relación con la cardiopatía isquemica, sin olvidar por supuesto las enfermedades autoinmunes.

Asumir el origen infeccioso de las enfermedades autoinmunes no supone dejar de lado el resto de las hipótesis explicativas de estas enfermedades, complejas bajo cualquier enfoque que se les dé. Las enfermedades infecciosas no son la única causa originaria de estas entidades patológicas, si bien, y es lo que pretendo mostrar con esta hipótesis, es la principal de las causas desencadenantes en algunos casos y originaria en muchos otros.

\section{SISTEMA INMUNE}

El sistema inmune, como todo sistema de respuesta defensivo, se encuentra diseñado para reconocer y destruir estructuras extrañas y respetar los tejidos propios. La base de este complejo sistema se encuentra en el denominado Sistema Mayor de Histocompatibilidad o por sus siglas HLA. Las moléculas de este sistema son glicoproteínas que se encuentran situadas en la membrana celular. Estas proteínas poseen una estructura terciaria, adoptando una conformación tridimensional, de tal forma que, los dos dominios externos forman un canal donde se unen los péptidos igual que una llave se ajusta a una cerradura.

Existen dos tipos de HLA, el de clase I se encuentra en todas las células nucleadas del organismo, es específico de cada individuo y esta diseñado solo para unirse y presentar en la superficie celular péptidos de la célula, por lo tanto son reconocidos como propios y no se desencadena una respuesta inmune. Únicamente cuando las células se encuentran parasitadas por virus o se transforman en neoplásicas, producen moléculas con epítopes para los cuales el sistema inmune no es tolerante, son reconocidos por los linfocitos T citotóxicos (CD 8) y destruidas.

Sin embargo el sistema HLA tipo II solamente se encuentra en la superficie de las células presentadoras de antígenos, es decir linfocitos B, células dendríticas y células de estirpe monocito/macrófago. Cuando un antígeno penetra en el organismo es captado por estas células y en los lisosomas se una a la proteína HLA tipo II que se ha sintetizado en el retículo endoplásmico, la variabilidad de esta proteína hace que solo puede unirse con aquellos antígenos que encajen en su hendidura, cuanto mejor encajen mayor afinidad tendrá por ellos. Una vez unidos, este complejo sale a la superficie de la célula, siendo el antígeno presentado a los linfocitos colaboradores o CD4 que ponen en marcha la respuesta inmune. Este es un paso fundamental del sistema, si un antígeno no puede unirse a una proteína HLA, este no podrá ser presentado y no existirá respuesta inmune.

¿Qué debe de suceder para que estos mecanismos se activen $\mathrm{y}$ ataquen a los tejidos del propio organismo?, o lo que es lo mismo ¿qué es la autoinmunidad?

Trabajo aceptado: 7 de Septiembre de 2001

Correspondencia: F. Blasco Patiño. Servicio de Medicina Interna II. Clínica Puerta de Hierro. C/ San Martín de Porres, nº. 28035 Madrid. 
Realmente la autoinmunidad es un concepto difícil de definir a la luz de los conocimientos actuales. En parte sería valida la definición recogida por Pérez Arellanos y cols. (1) en su revisión sobre la autoinmunidad, definiéndola como la pérdida de la autotolerancia, es decir de la capacidad del sistema inmunológico de respetar los tejidos propios. Esta definición es incompleta pues no tiene en cuenta que puede existir autoinmunidad sin alteración de los mecanismos de la autotolerancia, sino por aparición de una intolerancia. Desarrollemos ahora estos dos conceptos.

La tolerancia a los tejidos propios se desarrolla pronto. En la fase de maduración del sistema inmune en el feto, durante la generación de los linfocitos, ocurre un hecho crucial en el devenir futuro del sistema inmune de cada individuo, es la fase de recombinación genética, que permite que los pocos genes que almacenan la información necesaria para la síntesis de inmunoglobulinas, se combinen entre sí permitiendo de esta manera la creación de millones de inmunoglobulinas capaces de reconocer infinidad de antígenos. Este proceso es totalmente aleatorio y determina que con las múltiples combinaciones posibles surgan anticuerpos que reconocen antígenos propios dando lugar a los linfocitos autorreactivos. En la mayoría de las personas no producen fenómenos de autoinmunidad puesto que existen mecanismos de autotolerancia que impiden la activación de estas células. El fracaso de estos podría desencadenar una respuesta autoinmune.

Sin lugar a dudas el principal mecanismo de autotolerancia es la delección clonal, con este termino se define la destrucción de los linfocitos T y B autorreactivos en el timo del feto. Se ha comprobado que existe un pool de estos linfocitos presentes en sujetos adultos sanos y sometidos a mecanismos que mantienen su situación de anergia, como son; la inhibición de expresión de receptores, el fracaso en el proceso de presentación de antígenos, etc.

Uno de los mecanismos más interesantes que explican la autotolerancia y que pueden facilitar el desarrollo de nuevos métodos terapéuticos es la teoría de la red idiotipo-antiidiotipo, desarrollada por Niels-Jerme (2). Básicamente establece que las inmunoglubulinas como todas las proteínas tienen un potencial antigénico, en base al cual, son capaces de generar anticuerpos frente a ellas, algunos dirigidos contra los epítopes de la región variable del anticuerpo, es decir la zona mediante la cual el anticuerpo reconoce y se une al antígeno. De esta forma el anticuerpo quedaría bloqueado, a su vez este anticuerpo bloqueante generaría otro anticuerpo estableciéndose una red en equilibrio dinámico que suprime la respuesta inmune frente a antígenos propios.

Queda establecido el concepto de autotolerancia y de cómo la perdida de los mecanismos reguladores puede inducir fenómenos de autoinmunidad. Pero es posible que se desarrollen fenómenos de autoinmunidad sin necesidad de que se alteren estos mecanismos, mediante la aparición de intolerancia inmunológica, y es a este nivel donde juegan un papel fundamental los microorganismos. Se ha probado que la respuesta inmune dirigida contra un organismo infeccioso, puede por similitud antigénica condicionar una agresión sobre tejidos humanos con los que guardan una similitud, y de otra parte también se ha comprobado experimentalmente que algunos virus inducen cambios en la superficie celular y que una estructura propia deja de ser reconocida como tal y es objeto de ataque por nuestro sistema inmune.

Sin embargo muy pocas personas que son infectadas por estos organismos desarrollan autoinmunidad y no todas las per- sonas que se exponen al mismo agente desarrollan la misma respuesta. Esto nos lleva a concluir que solo en individuos susceptibles y por lo tanto genéticamente preparados es posible el desarrollo de enfermedades inmunes. La importancia del perfil genético en las enfermedades autoinmunes, viene establecida con la relación que se ha establecido entre diferentes enfermedades y determinados Antígenos del Sistema Mayor de Histocompatibilidad, el predominio de estas enfermedades en sujetos de raza negra o en del sexo femenino, aunque aquí se atribuye mas importancia a la acción de los estrógenos sobre la activación de linfocitos B autorreactivos o la expresión del HLA.

Es por lo tanto en el HLA donde radica la base de todo el proceso de autoinmunidad, y es en su polimorfismo (puede tener infinidad de formas de presentación espacial) donde radica la base de la susceptibilidad genética en el contexto de las enfermedades autoinmunes, de hecho la sustitución de un solo aminoácido en la cadena que conforma esta proteína, es suficiente para cambiar la conformación espacial de la misma, alterando de esta manera la afinidad (capacidad de acoplar) que tiene por el antígeno. Así Moret el al (3), observaron que en más del $90 \%$ de las cadenas proteicas que conforman el HLA DQB, HLA que confiere susceptibilidad a los individuos con diabetes tipo 1, existe un aminoácido neutro en la posición 57 , mientras que los individuos que no asociaban diabetes y presentaban este mismo haplotipo HLA tenían un ácido aspártico en dicha posición.

La importancia de este concepto explicaría porque las enfermedades autoinmunes se asocian a un determinado HLA, porque hay sujetos sanos que poseen este HLA y no padecen nunca la enfermedad, (ya que puede haberse producido una pequeña mutación, la perdida o sustitución de un aminoácido conlleva un cambio en su conformación espacial, y el antígeno ya no puede acoplarse a este HLA y ser presentado), porque un mismo HLA se puede asociar a diferentes manifestaciones clínicas, en función de donde se halla producido la mutación o quien sabe si incluso esta mutación puede determinar que el HLA tipo II acoplé proteínas propias y las presente al sistema inmune.

De todo lo dicho se puede deducir que el nivel de susceptibilidad no vendría determinado sólo por presentar un determinado HLA, sino que los cambios serían aún más discretos afectando a la estructura primaría de la proteína, esto es a la disposición de los aminoácidos. Los individuos susceptibles presentarían pequeñas modificaciones en el sistema HLA que permiten acoplar y presentar antígenos al sistema inmune, y no así las personas que no tengan estos cambios.

La enfermedad tipo que apoya con más claridad la importancia de estos hechos es sin duda la espondilitis anquilosante, el riesgo relativo de desarrollar la enfermedad en sujetos HLA B27 es de 97, es decir estos individuos tienen 97 veces más probabilidad de presentar la enfermedad que aquellos individuos que no lo poseen, a su vez sólo el $5 \%$ de los sujetos que presentan el HLA B27 desarrollan enfermedad, y de otro lado otros pacientes con HLA B27 positivo, sólo desarrollan uveitis, o bien un síndrome de Reiter.

Y retomando el tema de esta hipótesis, ¿cuáles son los agentes que en contacto con estos sujetos susceptibles pueden desarrollar una agresión contra los tejidos propios? Entre los agentes descritos, hay sustancias químicas (medicamentos), agentes físicos (luz ultravioleta), células neoplásicas, pero el más universal de todos los agentes, lo constituyen los agentes infecciosos que poseen una serie de características que les convierten en los agentes ideales. 


\section{INFECCIÓN Y AUTOINMUNIDAD}

Son muchas las hipótesis que tratan de explicar un fenómeno tan complejo como es este, objeto de la actual revisión. Me limitaré a referir las principales respuestas que en la actualidad gozan de mas importancia a la hora de explicar las enfermedades autoinmunes.

\section{ALTERACIÓN DE LA APOPTOSIS}

Como antes he referido un mecanismo básico entre los mecanismos de autotolerancia es la muerte de los linfocitos autorreactivos en las primeras fases del desarrollo, en el proceso de la selección tímica, en el cual los linfocitos que reconocen antígenos propios son destruidos. Se ha demostrado en modelos murinos que la alteración de este proceso condiciona la aparición de fenómenos de autoinmunidad, siendo a su vez este, el mecanismo esgrimido en humanos para explicar el síndrome linfoproliferativo autoinmune (4).

\section{EQUILIBRIO Th1-Th2}

Los linfocitos Th1 parecen estar implicados en la secreción de citoquínas como la Il-2, INF-alfa y FNT-beta, que actuarían favoreciendo el proceso de expansión clonal y la citotoxicidad celular.

De otro lado los linfocitos Th2 secretarían Il-4, Il-5,6 y 10 que según algunos autores protegerían frente a fenómenos autoinmunes. El desequilibrio entre estos dos tipos de linfocitos a favor de los primeros condicionaría el desarrollo de enfermedades autoinmunes, sin embargo los diferentes ensayos realizados al respecto muestran respuestas contradictorias, y cabria pensar que las alteraciones de las citoquínas con más una consecuencia que una causa de los procesos de autoinmunidad.

\section{AGENTES INFECCIOSOS}

Como he referido previamente en la introducción, desencadenante principal de las enfermedades autoinmunes. Los mecanismos por los que actúan son muchos:

-Reacción cruzada por similitud antigénica entre una estructura (polisacárido, proteína, glicoproteínas, lipopolisacárido) del germen con una orgánica, que guarda la misma conformación espacial y que determina que los anticuerpos formados contra el germen ataquen al tejido humano.

-Expresión de péptidos de membrana no propios de la célula y si de un virus con el consiguiente ataque del sistema inmune contra una zona que no reconoce.

-Activación policlonal de linfocitos B autorreactivos que se encuentran en situación de anergia.

- Alteración de la red idiotipo-antiidiotipo.

-Ruptura de santuarios inmunológicos. Se pone en contacto con el sistema inmunológico células que nunca habían sido presentadas y por tanto extrañas para nuestro sistema inmune.

-Modificación en la expresión del HLA, bien aumentando la expresión de las moléculas HLA en la membrana celular de los tejidos infectados, bien mediando su expresión en células que habitualmente no lo expresan.

La asociación entre infección y autoinmunidad no es un concepto que halla surgido en los últimos años, Esta se ha eviden- ciado desde hace décadas, el ejemplo clásico es la relación entre la infección por Streptococo del grupo A y la fiebre reumática.

En 1968 Gobstein y cols. (5) publicaron en Nature la existencia de anticuerpos dirigidos contra polisacáridos del Streptococo del grupo A que reaccionaban de forma cruzada por su similitud antigénica con una glicoproteína situada en las válvulas cardiacas humanas y bovinas. En ese mismo año Sandson y cols. (6) describen la similitud entre la hialuronidasa de la cápsula del Streptococo del grupo A y el tejido conectivo humano, esta respuesta se daba más en sujetos con HLA A5, atribuyendo varios autores esta asociación a una selección genética de la respuesta inmune frente a determinados antígenos estreptococicos.

El Streptococo nos permite ver, por un lado como un mismo germen puede dar diversas respuestas autoinmunes al ser atacado por diferentes anticuerpos que reaccionan de forma cruzada con los tejidos humanos y de otro lado estableciendo una posible base genética que determina que se dé con más frecuencia en aquellos sujetos que tienen un HLA específico.

Es el modelo de base para explicar el fenómeno de reacción cruzada, en este modelo una persona sana es infectada por un microorganismo (puede darse también con agentes químicos y con células tumorales), el sistema inmune lo detecta y surge una respuesta defensiva en forma de la liberación de anticuerpos por linfocitos B activados que reconocen la estructura antigénica que ha motivado su liberación. Cualquier microorganismo que tenga este antígeno es atacado y destruido, pero también cualquier otra célula que posea este antígeno, o una estructura de conformación similar que permita el acoplamiento del anticuerpo, aunque esta célula sea de nuestro propio organismo.

\section{Modelo de reacción cruzada}

Esta forma de respuesta autoinmune esta adquiriendo cada vez mayor importancia tal y como se desprende de numerosas publicaciones que avalan este modelo, y que engloban a la mayoría de las enfermedades autoinmunes.

Lunardi y cols. (7) evidenciaron en 10 pacientes que cursaban con episodios de artritis simétrica catalogados como artritis reumatoide, la existencia de Acs (anticuerpos) IgM frente a parvovirus B-19, indicador de infección aguda por este virus. Los autores del trabajo sintetizaron anticuerpos frente a este germen tomando como base péptidos víricos obtenidos de la región que codificaba la proteína 1 y 2 del virus. En una segunda fase, cruzaron los anticuerpos obtenidos con células humanas, reconociendo y fijando queratina, colágeno tipo 2, DNA monocatenario y cardiolipina.

En esta misma línea Hemmerich y cols. (8) han demostrado la relación existente entre lupus eritematoso sistémico (LES) y la enfermedad mixta del tejido conectivo (EMTC) con la infección por Clamydia tracomatis. Los autores de este trabajo destacan la existencia de una alta homogeneidad entre la secuencia 264-286 de la RNA polimerasa de la Clamydia y la proteína ribosomial L7. Esta proteína es una de las dianas más frecuentes en las enfermedades autoinmunes y los Anticuerpos anti-L7 no serian sino anticuerpos frente a Clamydia trachomatis.

Otro ejemplo lo constituye el virus de la hepatitis C. La hepatitis $\mathrm{C}$ es una de las enfermedades que se asocia a fenómenos de autoinmunidad; crioglobulinemia mixta, glomerulonefritis membrano-proliferativa, poliartritis etc. Existen secuencias análogas entre las proteínas del core, la envoltura y la región NS5 del VHC y el citocromo P450 2D6 (9), quedaría 
por establecer si los anticuerpos contra el citocromo intervienen en el origen de estos procesos.

Pero sin lugar a dudas, dos son las enfermedades donde este mecanismo se pone más claramente de manifiesto. La enfermedad de Behçet tiene más incidencia entre los sujetos que presentan una mayor frecuencia de infecciones en orofaringe. En estos pacientes se han aislado cepas de Streptococo sanguis, sobre todo KTH1 3 y 4 no presentes en la población general. Estas cepas comparten secuencias aminoacídicas con proteínas de la mucosa oral que se comportarían como antígenos (10). Así la administración de antígenos procedentes de esta cepa en pacientes con Behçet, desencadena brotes cutáneo mucosos, oculares y articulares, lo que confirma, el papel que desarrollan los anticuerpos generados frente a estos en la aparición de la enfermedad.

La otra enfermedad o conjunto de enfermedades son las polirradiculopatías inflamatorias desmielinizantes autoinmunes, tanto en su forma aguda también denominada Síndrome de Guillain-Barré (SGB), como en la forma crónica. 2/3 de los pacientes, tienen antecedentes de infección respiratoria o gastrointestinal entre la $1^{\mathrm{a}}$ y $3^{\mathrm{a}}$ semana antes del inicio del cuadro, el cual se desarrolla coincidiendo con la elevación de los anticuerpos. De hecho la clínica puede ser consecuencia de la inmunidad generada tras la vacunación frente a enfermedades como; la gripe, sarampión, poliomielitis, rubéola, rabia o fiebre tifoidea.

Son muchos los gérmenes que se han relacionado con estos síndromes, destacando Mycoplasma pneumoniae (11), éste es uno de los agentes que se han relacionado con más procesos de autoinmunidad sobre todo en el sistema nervioso. Estos cuadros se precede en el $80 \%$ de los casos de infecciones respiratorias sintomáticas, desarrollándose la clínica neurológica 1-4 semanas después coincidiendo con la elevación de los anticuerpos. Existe similitud de proteínas de la esfingomielina con glicoproteínas de la envoltura de $M y c o$ plasma.

Pero sin lugar a dudas el germen que más se ha relacionado con este síndrome el Campilobacter jejuni. Yuki y cols. (12) estudiaron un grupo de 8 pacientes con SGB y antecedentes de gastroenteritis en los días previos. En 4 de ellos demostraron infección aguda por esta bacteria. Valiéndose de test de inmunoabsorción realizados sobre el serotipo HS-19, observaron la presencia en polisacáridos de la cápsula de $C$. jejuni, del epítope Ga1Nac-GD1a, presente en gangliósidos que forman parte de la estructura de nervios periféricos, y probable responsable del mecanismo de respuesta cruzada. El 26$41 \%$ de los casos de SGB (13), e incluso el $66 \%$ de los estudios realizados en China (14), atribuyen a $C$. jejuni el origen de este cuadro, siendo esta relación más marcada en la variante de Miller-Fisher (15).

Las infecciones por CMV representan el 10-20\% de los casos de SGB (16), los anticuerpos dirigidos contra este virus reaccionarían por similitud con GM2 y glucolípidos.

Otras enfermedades en las que se implica este mecanismo son: la espondilitis anquilosante, estableciéndose una similitud antigénica de la Klebsiella pneumoniae y estructuras articulares en sujetos susceptibles HLA-B27 (17). La artritis reactiva que aparece tras gastroenteritis por Salmone lla enteritidis (18), Y. enterocolítica (19) o Shigella sonnei (20), o tras una infección genitourinaria con Clamydia tra chomatis y Ureaplasma urealyticum, es el llamado síndrome de Reiter (21).

\section{Modificación de la estructura antigénica celular}

Otro mecanismo mediante el cual se puede desencadenar respuestas autoinmunes es la modificación de las proteínas que expresa la célula. Este modelo es muy característico de las infecciones víricas. El virus penetra en la célula e introduce su material genético utilizándola para la síntesis de sus propias proteínas. Este material vírico puede incorporarse a la membrana celular o permanecer en el interior de la célula, al ser presentado en la superficie celular junto al HLA tipo I, estas no son reconocidas desencadenándose la respuesta del sistema inmune.

Existen muchos agentes biológicos que podrían utilizar esta vía. Hay diversas enfermedades donde se han aislado en tejidos, gérmenes o material procedente de los mismos si bien no esta claro su posible papel. En el año 1979 Gitnick y cols. (22) obtuvieron fragmentos de un virus RNA en el colon de pacientes con colitis ulcerosa. En la enfermedad de Crohn se ha aislado en tejido intestinal Mycobacteria paratuberculosis, al igual que en el intestino de animales afectos por enfermedad de Johne, de características clínicas muy similares a la enfermedad de Crohn (23).

En la dermatomiositis mediante la utilización de la PCR, se ha extraído genoma vírico en las fibras musculares, en la mayoría de los casos descritos se trata de retrovirus (24).

El ejemplo más claro ha sido publicado por M. See y J. G Tiller (25). La diabetes mellitus tipo 1 es una enfermedad autoinmune en la cual existen anticuerpos dirigidos contra las células beta de los islotes de Langerhans, concretamente contra la proteína $64 \mathrm{Kda}$ situada en estas células, denominándose a estos ACS, IcAs. Esta proteína se ha aislado tanto en ratones como en humanos. Los autores de este trabajo inocularon en una cepa de ratones susceptibles genéticamente (CD-1) la variedad $\mathrm{E}_{2}$ del virus Cosakie $\mathrm{B}_{8}$. En los días siguientes a la inoculación se redujeron los niveles de ARN viral en páncreas coincidiendo con la elevación de los anticuerpos contra la proteína 64 Kda que se había expresado en la superficie celular y que inicialmente no tenían, apareciendo tras la infección. Todos los ratones desarrollaron diabetes.

\section{Activadores policlonales}

Diferentes agentes biológicos son capaces de producir una activación policlonal de los linfocitos B, células con un gran potencial, capaces de generar gran cantidad de anticuerpos, sobre todo la población B-1 muy implicada en la secreción de autoanticuerpos. Muchos de estos linfocitos pertenecerían al pool de linfocitos autorreactivos que no han sido eliminados.

Entre los agentes implicados se ha demostrado la importancia del Mycoplasma (26), aunque es el citomegalovirus el agente considerado con mayor capacidad de activación de clonas. Se le ha relacionado con la inducción de Acs frente a glicoproteínas de la mielina en el SGB (27), o con los Acs antifosfolípido, etc. (28). También el virus de la hepatitis $\mathrm{C}$ es un importante activador de clones, siendo este el mecanismo esgrimido como origen de la crioglobulinemia que aparece en pacientes con esta enfermedad.

\section{Modificación del HLA}

Las infecciones víricas provocan en el organismo una respuesta defensiva en la cual intervienen numerosas sustancias, entre ellas los interferones (IFN). El IFN alfa aumenta la expre- 
sión de las moléculas de clase I, y IFN gamma las moléculas de clase II. Si tenemos en cuenta que es el sistema HLA donde se deben fijar los antígenos, si existe una sobreexpresión del mismo se facilita el acoplamiento y la presentación. Este fenómeno se ha implicado en los fenómenos de autoinmunidad que aparecen tras infecciones por virus con el desarrollo de miocarditis, pericarditis etc. (3).

Pero el cambio también puede ser cualitativo. En algunas enfermedades autoinmunes se ha observado la expresión del HLA tipo II en células que habitualmente no lo expresan. Un ejemplo lo constituye la esclerosis múltiple, en los astrocitos de los pacientes con esta enfermedad aparece el HLA- DR2 (3), actuando como células presentadoras de antígenos, el mismo mecanismo que desempeñarían las células epiteliales de las glándulas exocrinas en la enfermedad de Sjögren (29).

\section{CONCLUSIONES}

Parece indudable la existencia de una base genética que determina la susceptibilidad de determinadas personas a sufrir enfermedades autoinmunes. Los estudios apuntan a cambios en la estructura primaria del HLA, que le permitirían acoplar antígenos y presentarlos.

Existen en el organismo de muchas personas linfocitos autorreactivos, bloqueados por unos mecanismos que determinan la autotolerancia a los propios tejidos, la alteración de estos mecanismos puede desencadenar procesos de autoinmunidad. Pero la autoinmunidad también aparece sin que intervengan estos mecanismos, por la acción de agentes externos o internos.

Se está poniendo de manifiesto la importancia que las infecciones tienen sobre el desarrollo de las enfermedades autoinmunes, bien mediante mecanismos de respuesta cruzada, modificación de las proteínas celulares, del HLA, o generando una respuesta policlonal.

El mejor conocimiento del genoma y estudios epidemiológicos amplios, permitirán en un futuro próximo poner de manifiesto los mecanismos íntimos de estas enfermedades y permitirán el desarrollo de nuevas terapias. “...no creo saber nada con sentido, ni supongo poder enseñar nada, ni a nadie mejorar ni convertir..." Fausto (Goethe).

\section{Bibliografía}

1. Pérez JL, Losa JE, Mateo F. Bases biológicas de la autoinmunidad. Rev Clin Esp 1995; 195: 45-52.

2. Jerme N. New inmunological teorit. Ann Immunol J.1975; 32c.

3. Morel PA, Dorman JS, Todd JA, Mc Devitt HO, Trucco M. Aspartic Acid at position 57 of the HLA DQB chain protects against type 1 diabetes: A family study. Proc Natl Acad Sci USA 1988; 85; 3111-5.

4. An inherited Disorder of Lymphocyte Apoptosis: The autoimmune Lymphoproliferative Syndrome. Ann Intern Med 1999; 130: 591-601.

5. Gobstein I, Rebeyotte P, Parlebas J, et al. Isolation front heart valves of glycopeptides which share immunological properties which Streptococcus haemolyticus group A polysaccharides. Nature 1968; 219: 286.

6. Sandson J, Hamuman D, Janis R, et al. Inmunologic and chemical similarities between the streptococcus and human connective tissue. Trass Assoc Am Phys 1968; 81: 249.

7. Lunardi C, Tiso M, Borgato L, Nanni L, Millo R, De Sandre G, et al. Chronic Parvovirus B-19 infection induces the production of antivirus antibodies with autoantigen binding properties. Eur J Inmunol 1998; 28: 3857-66.

8. Hemmerich P, Neu E, Mach M, Peter HH, Kraveinvel U, Von Mikecz A. Correlation between Chlamydia infection and autoinmune response: molecular mimicry between RNA Polymerase major sigma subunit from Chlamydia trachomatis and human L7. Eur J Inmunol. 1998; 28: 3857-66.

9. Manns M, Obermayer-Straub P: Cytochromus P450 and Uridine Triphosphate Glucuronosyltransferes: Model autoantigens to study drug induced, virus induced and autoinmune liver disease. Hepatol 1997; 26: 1054-1064.

10. López-Soto A, Boré A. Font J. Enfermedad de Behçet: En enfermedades autoinmunes Font J, Cervera R, Ingelmo M.Eds. Barcelona MRA, 1998: 305-325

11. Blasco F, Gómez J, Román F, Pérez Maestu RM. López de Letona J, Garrido-Arroquia C. Meningitis aséptica por Mycoplasma pneumoniae. Enferm Infecc Microbiol Clin 2000; 168: 94-95.

12. Yuki N, Taki T. Honda S. Antibody to Ga1Nac-GD1a and Ga1NacGM1c in Guillain-Barré Syndrome subsequent to Campylobacter jejuni. J Neuroinmunol 1996; 71: 155-161.

13. Jacob BC, van Doorm PA, Schmitz PM, et al. Campylobacter jejuni infections and anti GM1 antibodies and Guillain-Barré syndrome. Ann Neurol 1996; 40: 181-187.

14. Ho TW, Mishu B, Li CY, et al. Guillain Barré Syndrome in northem

China. Relationships to Campylobacter jejuni infection and anti-glycolipid antibodies. Brain 1995; 118: 597-605.

15. Hahn A. Guillain-Barre Syndrome. Lancet 1998; 352: 635-641.

16. Winer JB, Hughes RAC, Anderson HJ, et al. A prospective study of acute idiophatic neuropathy: antecedent events. J Neurosurg Pshychiatry 1988; 51: 613-618.

17. Eastmond CJ. Epidemic reactive arthritis. Ann Rheum Dis 1990; 49: 73-74.

18. Hannu T.J, Leirisalo-Repo M. Clinical picture of reactive Salmonella arthritis. J Rheumatol 1988; 11: 1668-1671.

19. Granfors K, Jalkanen S, Von Essen R, et al. Yersinia antigens in synovial-fluid cell from patients witch reactive arthritis. N Engl J Med 1989; 320: 216-220.

20. Lauhio A, Lahdevirta J, Janes R, Kontiainen S, Repo H. Reactive arthritis associated with Shigella sonnei infection. Arthritis Rheum 1988; 31: 1190-1193.

21. Kear A. Reiter's syndrome and reactive arthritis in perspective. N Engl J Med 1983; 309: 1606-1615.

22. Gitnick Gl, Rosen VJ, Arthur MH, Herteck SA. Evidence for the isolation of a new virus from ulcerative colitis patients. Dig Dis Sci 1979; 24: 609-15.

23. Thomson AB, Sadwski D, JenKims R, Wild G. Budenoside in the management of patient with Crohn's disease. Can J Gastroenterol 1997; 11: $255-260$.

24. Campo A, Hausman G, Herrero C. Dermatomiositis. En enfermedades autoinmunes. Font J, Cervera R, Ingelmo M. Eds. Barcelona MRA 1998; 215-259.

25. See M, Tilles JG. Pathogenesis of virus-induce diabetes in mice. J Infect Dis 1995; 171: 1131-1138.

26. Biberfeld G. Antibodies to brain and other tissues in cases of Mycoplas ma pneumoniae infection. Clin Exp Immunol 1971; 8: 319-33.

27. Yuki N, Yamamoto T, Hirata K. Correlation between Cytomegalovirus infection and IgM Anti-MAG/SGPG antibody-associated neurophaty. Ann Neurol. 1988; 44: 408-410.

28. Hwee-Ming Ch, Nor Shahidah K. Induction of Antiphospholipid autoantibody during Cytomegalovirus infection. Clin Infect Dis 1997; 25: 1493.

29. Moutsopoulos HM. Síndrome de Sjögren. In: Fauci A.S, Braunwald E, Isselbacher KJ, et al. editors. Harrison Principios de Medicina Interna. 14th ed. Madrid: McGraw-Hill Interamericana de España, 1988; 2160-2163. 